\title{
Schoolteachers as candidates to be basic life support trainers: A simulation trial
}

Cristina Jorge-Soto ${ }^{1,2}$, Maite Abilleira-González ${ }^{3}$, Martin Otero-Agra ${ }^{4}$, Roberto Barcala-Furelos ${ }^{1,2}$, Cristian Abelairas-Gómez ${ }^{1,2}$, Łukasz Szarpak ${ }^{5}$, Antonio Rodríguez-Núñez ${ }^{1,2,6,7}$

${ }^{1}$ CLINURSID Research Group, University of Santiago de Compostela, Spain

${ }^{2}$ School of Nursing, University of Santiago de Compostela, Spain

${ }^{3}$ Faculty of Physical Activity and Sport Sciences. University of Vigo, Spain

${ }^{4}$ School of Nursing. University of Vigo, Spain

${ }^{5}$ Lazarski University, Warsaw, Poland

${ }^{6}$ Pediatric Emergency and Critical Care Division, Clinical University Hospital,

University of Santiago de Compostela, Spain

${ }^{7}$ Institute of Research of Santiago (IDIS) and SAMID Network, Santiago de Compostela, Spain

\begin{abstract}
Background: The aim was to assess future schoolteachers' basic life support (BLS) knowledge and willingness to include this content in school lessons. The aim was also to determine the learning effect of a brief BLS hands-on training session, supported by real-time feedback.

Methods: A convenience sample of 98 University students of Educational Sciences and Sports were recruited. The training program consisted of brief theoretical and hands-on interactive sessions with a 2/10 instructor/participants ratio. Knowledge and willingness was assessed by means of a survey. Chest compressions (CC) and ventilation quality were registered in 47 cases during 1 min cardiopulmonary resuscitation (CPR) tests.

Results: Fifty-eight percent of subjects declared to know how to perform CPR, $62 \%$ knew the correct chest compression/ventilation ratio but only one in four knew the CC quality standards. Eighty-eight percent knew what an automated external defibrillator (AED) was; willingness to use the device improved from $70 \%$ to $98 \%$ after training. Almost half of CCs were performed atan adequate rate. Men performed deeper compressions than women $(56.1 \pm 4.03 \mathrm{~mm}$ vs. $52.17 \pm 5.51 \mathrm{~mm}, p=0.007)$, but in both cases the mean value was within recommendations. Full chest recoil was better in women $(72.2 \pm 32.8 \%$ vs. $45.4 \pm 32.9 \%, p=0.009)$. All CCs were delivered with correct hand positions.

Conclusions: Brief hands-on training supported by real-time feedback of CPR quality helps future schoolteachers improve their knowledge, self-confidence and CPR skills. BLS training should be implemented in University curricula for schoolteachers in order to promote their engagement in effective BLS training of schoolchildren. (Cardiol J 2019; 26, 5: 536-542)
\end{abstract}

Key words: teachers, basic life support, cardiopulmonary resuscitation, automated external defibrillation, training

\section{Introduction}

The European Resuscitation Council (ERC) guidelines endorsed the recommendation that all citizens should be taught cardiopulmonary resuscitation
(CPR) [1-3]. At least, half of out-of-hospital cardiac arrests (OHCA) are witnessed [4, 5], but although bystander resuscitation could improve survival and outcomes [6], the actual rate of CPR initiated by bystanders remains very low in most countries [7].

Address for correspondence: Associate Professor Łukasz Szarpak, PhD, Lazarski University, ul. Świeradowska 43, 02-662 Warszawa, Poland, e-mail: lukasz.szarpak@gmail.com

Received: 4.07.2018

Accepted: 8.07.2018 
Schools had been pointed out as a perfect environment to start CPR training [8]; in fact, children are considered to be an ideal target group to train in basic life support (BLS) because they are also situated in a vital stage of easy learning $[9,10]$.

The inclusion of schoolteachers as a key element of schoolchildren BLS training has been endorsed by international initiatives like Kids Save Lives [11-13], which emphasise the teacher role as facilitator and/or trainer due to their pedagogic abilities.

Previous studies have reported that teachers have willingness to provide this instruction and it seems that even a very brief BLS training program might be enough to improve their knowledge, skills and self-confidence $[14,15]$. This kind of training could ease formation access as well as regular retraining $[2,16,17]$ without significant interference or changes to the regular scholar curriculum. In addition, feedback and self-instructed learning seem to be useful tools to strengthen CPR learning $[18,19]$.

Thus, the aim of the present study was to assess future schoolteachers' BLS knowledge and willingness to include this content in school lessons, as well as to determine the learning effect of a brief BLS training session, supported by real-time feedback by means of quantitative measurement of CPR performance.

\section{Methods}

\section{Participants}

A convenience sample of 98 University students (62 men and 36 women) of Physical Activity and Sport Sciences at the University of Vigo (Spain) were recruited for this study.

\section{Study design}

The training program consisted of theoretical and hands-on sessions and was conducted by instructors certified in basic and advanced life support. The theory session lasted $30 \mathrm{~min}$ and content included the chain of survival (how to recognise a cardiac arrest, call of medical emergency service, how to perform BLS, call for an automated external defibrillator [AED] and the importance of public access of defibrillation by means of AED). For practice, the sample was distributed into groups with a 10/2 participants/instructors ratio. The handson session lasted $1 \mathrm{~h}$, and participants trained 15 min "chest compressions (CC) only" CPR, 15 min pediatric CPR, 15 min real time quality feedback CPR (compressions and ventilations) and $15 \mathrm{~min}$ for AED use. After practice, CPR skills of 47 participants were assessed by means of a practical test consisting of 1-min CPR (CC and ventilations). Participants used a Laerdal Mini Anne manikin and Laerdal Resusci Anne manikin (Laerdal, Stavanger, Norway) for CPR practice with a Laerdal AED trainer (Fig. 1).

Participation was voluntary and no personal incentive for participation was given. The study respected the Helsinki Declaration and was approved by the local institutional review board (Research Ethics Committee of the University School of Education and Sports Sciences, University of Vigo, Spain).

\section{Measurement tools}

First of all, a questionnaire was given to all participants. The survey included questions about personal prior training or experiences and basic knowledge in CPR and AED management. The same questionnaire was completed after hands on training.

Twenty-three questions formed the survey and the main topics were: Prior training in BLS (questions 1-4); CPR knowledge and prior experience as a bystander (questions 5-13); CPR quality standards and willingness to teach BLS (questions 14-17); AED knowledge and willingness to use the device (questions 18-21); and a personal opinion about the importance of BLS training programs (questions 22-23). Test included dichotomous, multiple choice answer and subjective opinion by means of a Likert scale. Questionnaires were encoded to preserve the anonymity of participants.

Cardiopulmonary resuscitation quality was assessed through the Laerdal Resusci Anne manikin and Laerdal PC Skill Reporting Software, version 2.4 , which measures chest compression and ventilation quality. Goals were set according to the 2015 quality standard established by the ERC [1].

Cardiopulmonary resuscitation quality metrics included mean compression rate (in $\mathrm{CC}$ per minute), percentage of $\mathrm{CC}$ at adequate rate, mean compression depth (in millimetres), percentage of compressions at adequate depth, percentage of $\mathrm{CC}$ with full-chest recoil, percentage of $\mathrm{CC}$ with adequate hands position, and mean estimated tidal volume (in millilitres).

\section{Statistical analysis}

Categorical data were described as absolute numbers and percentages. Continuous data were described by mean and standard deviation (SD). The Kolgomorov-Smirnov test was used to study 


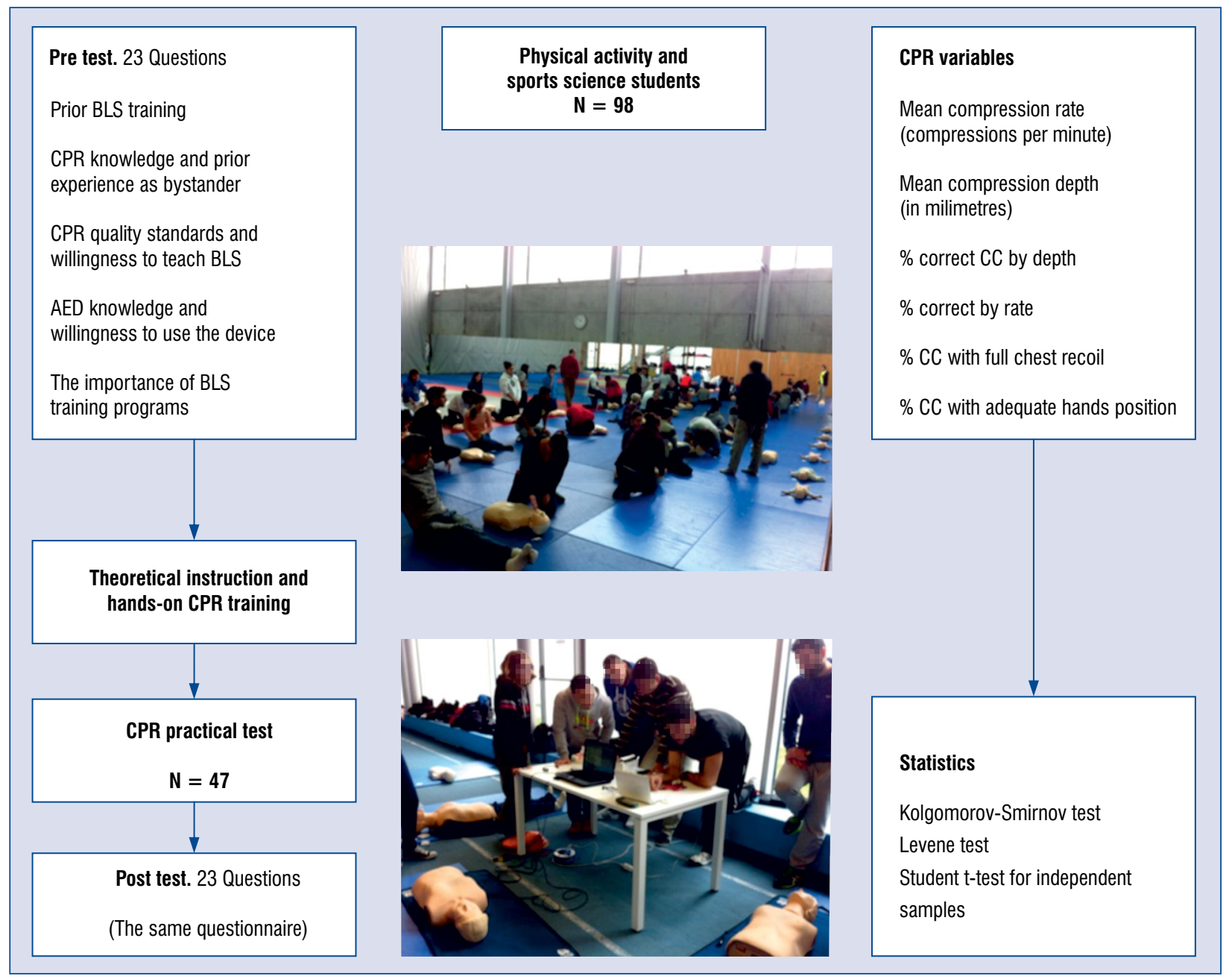

Figure 1. Study design. Stages of sample knowledge evaluation and practical test. Cardiopulmonary resuscitation (CPR) variables and statistics; AED — automated external defibrillator; BLS — basic life support; CC — chest compressions.

normal distribution of continuous variables. The equality of variances was determined using the Levene test. Correlations between continuous data were assessed using the Student t-test for independent samples to assess quality CPR differences between the Men Group and Women Group as well as between two response groups of question 6. SPSS Statistics 20.0 Software was used for statistical analyses. In all analyses, a significance level of $\mathrm{p}<0.05$ was considered.

\section{Results}

The study included 98 participants, $62(63.3 \%)$ men and $36(36.7 \%)$ women. Mean age was $23.66 \pm 5.79$ years.

Prior training data of the sample are shown in Table 1. All participants affirmed to know what CPR is. Fifty-eight percent declared to know how to per- form CPR on an adult victim, a figure that increased to $100 \%$ after training. More than half of participants $(62.2 \%)$ knew the correct chest compressions/ventilations ratio in an adult but only $22.4 \%$ answered correctly to the question about the target compression rate and $23.5 \%$ of the recommended compression depth. After taking part in the training program, 99\% participants knew the correct chest compressions/ ventilations ratio; $92.9 \%$ knew the correct $\mathrm{CC}$ rate and $85.7 \%$ the adequate $\mathrm{CC}$ depth.

Fifty-nine $(60.2 \%)$ participants declared to have been trained in CPR before the study, 50\% of them knew the correct chest compressions/ ventilations ratio, 35\% knew $\mathrm{CC}$ recommended rate and 33\% the correct $\mathrm{CC}$ depth goal (Table 2).

With regard to their prior response as bystanders, only 8/98 (8.2\%) had witnessed an emergency situation and $4.1 \%$ had participated in actual resuscitation manoeuvres. 
Table 1. Prior cardiopulmonary resuscitation (CPR) training characteristics and CPR quality questions answered by participant who had received prior CPR training.

\begin{tabular}{llc}
\hline Parameters & & Frequency (\%) \\
\hline Prior CPR training characteristics & Participants with prior CPR training & $59(60.2 \%)$ \\
& CPR training as part of a specific subject & $30(30.6 \%)$ \\
& Training in the last 3 months & $50(51 \%)$ \\
& Participants who performed real time feedback CPR & $51(52 \%)$ \\
Participants with prior training $(\mathrm{n}=59)$ & Chest compressions/ventilations rate (30:2) & $50(87.7 \%)$ \\
& Chest compressions per minute $(100-120 \mathrm{cpm})$ & $20(35.1 \%)$ \\
& Chest compressions depth (50-60 mm) & $19(33.3 \%)$ \\
\hline
\end{tabular}

cpm - compressions per minute

Table 2. Comparison of cardiopulmonary resuscitation quality variables by sex of the participant.

\begin{tabular}{lccc}
\hline & Men $(\mathbf{n}=29)$ & Women $(\mathbf{n}=18)$ & $P^{*}$ \\
\hline Mean compression rate [cpm] & $112.8 \pm 9.16$ & $111 \pm 7.42$ & 0.488 \\
Mean compression depth [mm] & $56 \pm 4.03$ & $52 \pm 5.51$ & 0.007 \\
Correct chest compressions by depth [\%] & $49.01 \pm 36.31$ & $54.4 \pm 30.80$ & 0.603 \\
Correct chest compressions by rate [\%] & $83.6 \pm 11.26$ & $87.9(9.41$ & 0.599 \\
Chest compressions with full chest recoil [\%] & $45.4 \pm 32.9$ & $72.2 \pm 32.85$ & 0.009 \\
Chest compressions with adequate hand positions [\%] & $100 \pm 0.00$ & $100 \pm 0.00$ & \\
\hline
\end{tabular}

*Student T test for independent samples; cpm — compressions per minute

The percentage of participants who knew what an AED increased from $87.8 \%$ before to $100 \%$ after training, and the number who declared to know how to use an AED (pre-test $38.8 \%$ vs. post-test $100 \%$ ). Most subjects declared the willingness to use an AED in an eventual emergency situation both pre-test (70.4\%) and post-test (98\%).

Eighty-five percent of participants considered that a specific First Aid subject is important for their academic training and $78.6 \%$ stated that this subject should be mandatory for all Physical Activity and Sports Science students, most of them would be willing to include this content in projects or didactic units with their students (pretest $71.4 \%$ and post-test $76.5 \%$ ). The number of participants who had considered their previous training as very efficient decreased from $48 \%$ to $34.7 \%$ after the current training. On the other hand, $34.7 \%$ participants considered their CPR skills as very insufficient initially, but after training $43.9 \%$ students described their CPR skills as "enough" and $29.6 \%$ as "effective".

Results of CPR quality metrics by sex are shown in Table 2 and Figure 2. During the 1-minute test, more than $80 \%$ of CCs were performed at an adequate rate. Mean compression depth goal $(50-60 \mathrm{~mm})$ was achieved by both groups with

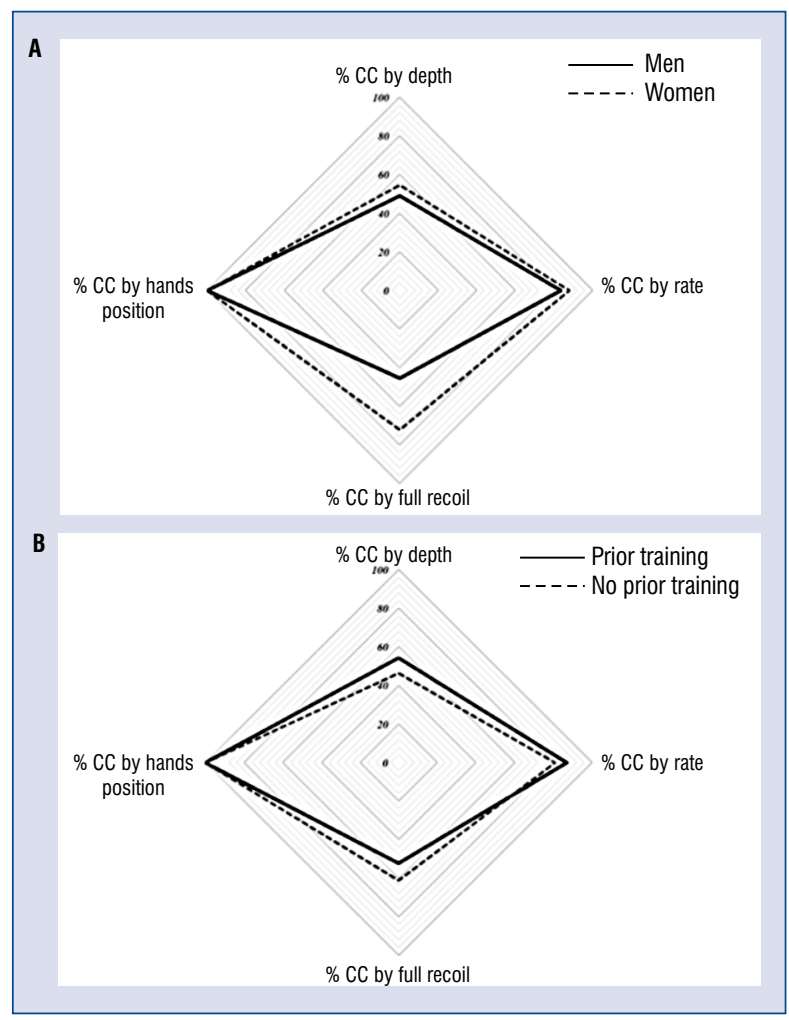

Figure 2. Cardiopulmonary resuscitation (CPR) quality standards. Comparisons by sex (A) and prior training (B); $\mathrm{CC}$ - chest compresions. 
deeper CC performed by men $(56.1 \pm 4.03 \mathrm{~mm}$ vs. $52.17 \pm 5.51 \mathrm{~mm}, \mathrm{p}=0.007)$. Full chest recoil was better in women $(72.2 \pm 32.8 \%)$ than in men $(45.4 \pm 32.9 \%, \mathrm{p}=0.009)$. All CCs were delivered with correct hand positions.

No significant differences were observed regarding prior CPR training of participants. Data are shown in Figure 2.

\section{Discussion}

Layperson CPR training is essential to increase bystander CPR rates and OHCA outcome [20]. Moreover, it is worth remembering that teaching how to act in life-threatening situations, including cardiac arrest resulting from myocardial dysfunction or arrhythmias, is a key element of public safety [21]. Although schools are seen as an ideal environment to involve citizens in BLS training, it is not clear however, which professionals are more suitable for teaching schoolchildren $[12,14$, $22]$. In the present study, it was found that a very brief BLS training program had a positive effect on Physical Activity and Sports Science student knowledge and willingness to include this topic in school lessons. Also, after a brief hands-on practice with quality feedback, most of them were able to perform CPR that fulfils quality standard goals.

In spite of more than half of the present sample $(60.2 \%)$ having declared to have received prior CPR training, less than $25 \%$ knew the correct CPR quality standards (CC per minute and CC depth). Results are comparable with those obtained by Bogle et al. [23] in a survey responded to by 267 University students (only $46.1 \%$ met CPR quality standards). Observations revealed that a training session lasting less than $2 \mathrm{~h}$ (30 min theory and 1 -h hands-on practice) was enough to improve CPR performance of $85 \%$ of subjects involved.

Very brief training programs could be an effective formative strategy for both adults and schoolchildren. Thus, 45 min training appears to be enough for $8^{\text {th }}$ grade students to improve their CPR and AED knowledge and skills [24]. This knowledge and skill retention was maintained for 2 months, getting worse at 4 months for participants who had not re-trained previously; this fact endorses the importance of periodic re-training $[25,26]$. A contemporary study has shown how opportunistic $5 \mathrm{~min} \mathrm{CC}$ feedback training was, and whether it was enough for laypeople to be able to surpass a $70 \%$ goal for most of the technical parameters in 2-min CC test [27]. In the present sample, brief training with quality feedback was effective in accomplishing a mean compression rate and depth quality standard as well as correct hand positions.

In countries where CPR is a mandatory part of school curriculum, bystander CPR is performed in more than $40 \%$ of OHCA and has been associated with double to triple survival rates [22]. The need of certified instructors could mean a practical and financial barrier for BLS training implementation. Thus, BLS training conducted by teachers could help to overcome this barrier. Prior studies have shown that primary school teachers, previously trained by medical staff, can teach BLS effectively [13, 22]. Most of the present participants (93\%) considered that First Aid training is important for their education, more than $90 \%$ thought their academic curriculum should include this specific subject and for $78 \%$ it should be mandatory. Thus, for future teachers, a good BSL training during their academic education seems to be relevant and could improve their self-confidence and willingness [28]. To include these contents in University student curricula could ease implementation of strategies that endorse the role of teachers in school BLS training as with the Kids Saves Lives initiative $[9,11,12]$.

Lukas et al. [12] have shown that BLS training provided by trained teachers is as effective as the training provided by emergency physicians, additionally, schoolchildren trained by teachers accomplished better knowledge marks. It can be assumed that teachers have practical expertise in youngster education and can obtain better results than instructors with a non-educational background. The use of school teacher staff for BLS training has many advantages, such as the ease of implementation for this instruction at school centres, to act as role models and to act as facilitator of instruction [11, 12]. In the last several years self-instruction models like the Relieve Game proposed by Semeraro et al. [11] have been seen as relevant for schoolchildren training; in this kind of training, teachers act as facilitators or guides for instruction but they do not play the trainer role.

Although it is not clear at what age schoolchildren are capable of effectively learning different aspects of First Aid, previous studies have pointed out that the age of 13 is the minimum age to be able to perform CPR with a similar quality to an adult [29]. Whereas around 9 years old, children can start to be trained in the knowledge and use of AED [30, 31]. Regardless, it seems to be positive to familiarize children with BLS from an early age [9]. Child's retention is good 1 year after a 1 -h BLS course and this retention is better than in adults regarding $\mathrm{CPR}$ 
compressions/ventilation ratio knowledge, this endorsed the idea that training schoolchildren is a good investment for the future [32].

\section{Conclusions}

Brief hands-on training helps to improve knowledge and self-confidence in BLS and CPR skills of future schoolteachers. BLS training should be implemented in the University curricula for schoolteachers to promote the engagement of these professionals in effective BLS training of schoolchildren as supported by initiatives such as Kids Save Lives.

\section{Conflict of interest: None declare}

\section{References}

1. Perkins GD, Handley AJ, Koster RW, et al. European Resuscitation Council Guidelines for Resuscitation 2015: Section 2. Adult basic life support and automated external defibrillation. Resuscitation. 2015; 95: 81-99, doi: 10.1016/j.resuscitation.2015.07.015, indexed in Pubmed: 26477420.

2. Greif R, Lockey AS, Conaghan P, et al. Education and implementation of resuscitation section Collaborators. European Resuscitation Council Guidelines for Resuscitation 2015: Section 10. Education and implementation of resuscitation. Resuscitation. 2015; 95: 288-301, doi: 10.1016/j.resuscitation.2015.07.032, indexed in Pubmed: 26477418.

3. Zideman DA, De Buck EDJ, Singletary EM, et al. European Resuscitation Council Guidelines for Resuscitation 2015 Section 9. First aid. Resuscitation. 2015; 95: 278-287, doi: 10.1016/j.resuscitation.2015.07.031, indexed in Pubmed: 26477417.

4. Sasson C, Rogers MAM, Dahl J, et al. Predictors of survival from out-of-hospital cardiac arrest: a systematic review and metaanalysis. Circ Cardiovasc Qual Outcomes. 2010; 3(1): 63-81, doi: 10.1161/CIRCOUTCOMES.109.889576, indexed in Pubmed: 20123673 .

5. Mozaffarian D, Benjamin EJ, Go AS, et al. Heart disease and stroke statistics--2015 update: a report from the American Heart Association. Circulation. 2015; 131(4): e29-322, doi: 10.1161/ CIR.0000000000000152, indexed in Pubmed: 25520374.

6. Holmberg M, Holmberg S, Herlitz J. Factors modifying the effect of bystander cardiopulmonary resuscitation on survival in outof-hospital cardiac arrest patients in Sweden. Eur Heart J. 2001; 22(6): 511-519, indexed in Pubmed: 11320981.

7. Vaillancourt C, Grimshaw J, Brehaut JC, et al. A survey of attitudes and factors associated with successful cardiopulmonary resuscitation (CPR) knowledge transfer in an older population most likely to witness cardiac arrest: design and methodology. BMC Emerg Med. 2008; 8: 13, doi: 10.1186/1471-227X-8-13, indexed in Pubmed: 18986547.

8. Colquhoun M. Learning CPR at school--everyone should do it. Resuscitation. 2012; 83(5): 543-544, doi: 10.1016/j.resuscitation.2012.03.004, indexed in Pubmed: 22425813.

9. Böttiger BW, Van Aken H. Kids save lives--Training school children in cardiopulmonary resuscitation worldwide is now endorsed by the World Health Organization (WHO). Resuscitation.
2015; 94: A5-A7, doi: 10.1016/j.resuscitation.2015.07.005, indexed in Pubmed: 26209417.

10. Lockey AS, Georgiou M. Children can save lives. Resuscitation. 2013; 84(4): 399-400, doi: 10.1016/j.resuscitation.2013.01.011, indexed in Pubmed: 23328405.

11. Semeraro F, Frisoli A, Loconsole C, et al. Kids (learn how to) save lives in the school with the serious game Relive. Resuscitation. 2017; 116: 27-32, doi: 10.1016/j.resuscitation.2017.04.038, indexed in Pubmed: 28476478.

12. Lukas RP, Van Aken H, Mölhoff T, et al. Kids save lives: a six-year longitudinal study of schoolchildren learning cardiopulmonary resuscitation: Who should do the teaching and will the effects last? Resuscitation. 2016; 101: 35-40, doi: 10.1016/j. resuscitation.2016.01.028, indexed in Pubmed: 26868079.

13. Böttiger BW, Bossaert LL, Castrén M, et al. Kids Save Lives - ERC position statement on school children education in CPR: "Hands that help - Training children is training for life”. Resuscitation. 2016; 105: A1-A3, doi: 10.1016/j.resuscitation.2016.06.005, indexed in Pubmed: 27339096.

14. Mpotos N, Vekeman E, Monsieurs K, et al. Knowledge and willingness to teach cardiopulmonary resuscitation: a survey amongst 4273 teachers. Resuscitation. 2013; 84(4): 496-500, doi: 10.1016/j. resuscitation.2013.01.023, indexed in Pubmed: 23376584.

15. Caseiro-Abadín M, Abelairas-Gómez C, Barcala-Furelos R. Aprendizaje del uso del desfibrilador mediante vídeo en futuros docentes de infantil y primaria. Trances. 2014; 6(4): 249-268.

16. Wang J, Ma Li, Lu YQ. Strategy analysis of cardiopulmonary resuscitation training in the community. J Thorac Dis. 2015; 7(7): E160-E165, doi: 10.3978/j.issn.2072-1439.2015.06.09, indexed in Pubmed: 26380744.

17. Abelairas-Gómez C, Barcala-Furelos R, Szarpak , et al. The effect of strength training on quality of prolonged basic cardiopulmonary resuscitation. Kardiol Pol. 2017; 75(1): 21-27, doi: 10.5603/KP.a2016.0165, indexed in Pubmed: 27878801.

18. Bobrow BJ, Vadeboncoeur TF, Spaite DW, et al. The effectiveness of ultrabrief and brief educational videos for training lay responders in hands-only cardiopulmonary resuscitation: implications for the future of citizen cardiopulmonary resuscitation training. Circ Cardiovasc Qual Outcomes. 2011; 4(2): 220-226, doi: 10.1161/ CIRCOUTCOMES.110.959353, indexed in Pubmed: 21386066.

19. Telec W, Klosiewicz T, Zalewski R, et al. Chain of survival used for a victim of sudden cardiac arrest in a public place. Disaster Emerg Med J. 2017; 2(3): 135-136, doi: 10.5603/ DEMJ.2017.0029.

20. Wissenberg M, Lippert FK, Folke F, et al. Association of national initiatives to improve cardiac arrest management with rates of bystander intervention and patient survival after out-of-hospital cardiac arrest. JAMA. 2013; 310(13): 1377-1384, doi: 10.1001/ jama.2013.278483, indexed in Pubmed: 24084923.

21. Freund B, Kaplan PW. A review of the utility of a hypothermia protocol in cardiac arrests due to non-shockable rhythms. Cardiol J. 2017; 24(3): 324-333, doi: 10.5603/CJ.a2017.0016, indexed in Pubmed: 28150290.

22. Toner P, Connolly M, Laverty L, et al. Teaching basic life support to school children using medical students and teachers in a 'peer-training' model--results of the 'ABC for life' programme. Resuscitation. 2007; 75(1): 169-175, doi: 10.1016/j.resuscitation.2007.03.009, indexed in Pubmed: 17482334.

23. Bogle B, Mehrotra S, Chiampas G, et al. Assessment of knowledge and attitudes regarding automated external defibrillators and cardiopulmonary resuscitation among American University 
Cardiology Journal 2019, Vol. 26, No. 5

students. Emerg Med J. 2013; 30(10): 837-841, doi: 10.1136/ emermed-2012-201555, indexed in Pubmed: 23148110.

24. Watanabe K, Lopez-Colon D, Shuster JJ, et al. Efficacy and retention of Basic Life Support education including Automated External Defibrillator usage during a physical education period. Prev Med Rep. 2017; 5: 263-267, doi: 10.1016/j.pmedr.2017.01.004, indexed in Pubmed: 28138421.

25. Niles D, Sutton RM, Donoghue A, et al. "Rolling Refreshers": a novel approach to maintain CPR psychomotor skill competence. Resuscitation. 2009; 80(8): 909-912, doi: 10.1016/j.resuscitation.2009.04.021, indexed in Pubmed: 19467759.

26. Sutton RM, Niles D, Meaney PA, et al. Low-dose, high-frequency CPR training improves skill retention of in-hospital pediatric providers. Pediatrics. 2011; 128(1): e145-e151, doi: 10.1542/ peds.2010-2105, indexed in Pubmed: 21646262.

27. González-Salvado V, Fernández-Méndez F, Barcala-Furelos R, et al. Very brief training for laypeople in hands-only cardiopulmonary resuscitation. Effect of real-time feedback. Am J Emerg Med. 2016; 34(6): 993-998, doi: 10.1016/j.ajem.2016.02.047, indexed in Pubmed: 26964823.
28. Sip M, Serniak B, Rogozinski D, et al. Tactical medicine inspiring civilian rescue medicine in the management of haemorrhage. Disaster Emerg Med J. 2018; 3(1): 15-21, doi: 10.5603/ DEMJ.2018.0004.

29. Abelairas-Gómez C, Rodríguez-Núñez A, Casillas-Cabana M, et al. Schoolchildren as life savers: at what age do they become strong enough? Resuscitation. 2014; 85(6): 814-819, doi: 10.1016/j.resuscitation.2014.03.001, indexed in Pubmed: 24614187.

30. Jorge-Soto C, Abelairas-Gómez C, Barcala-Furelos R, et al. Automated external defibrillation skills by naive schoolchildren. Resuscitation. 2016; 106: 37-41, doi: 10.1016/j.resuscitation.2016.06.007, indexed in Pubmed: 27353288.

31. Jorge-Soto C, Abelairas-Gómez C, Barcala-Furelos R, et al. Learning to use semiautomatic external defibrillators through audiovisual materials for schoolchildren. Emerg Rev SocEsp Med Urgenc Emerg. 2016; 28(2): 103-108, indexed in Pubmed: 29105431.

32. Baldi E, Bertaia D, Contri E. School children learn BLS better and in less time than adults. Resuscitation. 2015; 88: e15-e16, doi: 10.1016/j.resuscitation.2014.12.034, indexed in Pubmed: 25600181. 